Cite this: Phys. Chem. Chem. Phys., 2012, 14, 14344-14353

\title{
Kinetic study of the reaction of vanadium and vanadium-titanium oxide cluster anions with $\mathrm{SO}_{2}$
}

\author{
Ewald Janssens, ${ }^{a}$ Sandra M. Lang, $\dagger^{a}$ Mathias Brümmer, ${ }^{b}$ Andrzej Niedziela, ${ }^{c}$ \\ Gabriele Santambrogio, $\ddagger^{b}$ Knut R. Asmis ${ }^{d}$ and Joachim Sauer ${ }^{c}$ \\ Received 29th June 2012, Accepted 22nd August 2012 \\ DOI: $10.1039 / \mathrm{c} 2 \mathrm{cp} 42201 \mathrm{~h}$
}

The reactivity of mass-selected $\mathrm{V}_{4} \mathrm{O}_{10}{ }^{-}$cluster anions towards sulphur dioxide is investigated in an ion trap under multi-collision conditions. Gas phase reaction kinetics are studied as a function of temperature $\left(T_{\mathrm{R}}=150-275 \mathrm{~K}\right)$. The binding energy of $\mathrm{SO}_{2}$ to $\mathrm{V}_{4} \mathrm{O}_{10}{ }^{-}$is obtained by analyzing the experimental low pressure rate constants, employing the Lindemann energy transfer model for association reactions in conjunction with statistical RRKM theory. In addition, infrared multiple photon dissociation spectroscopy is used in conjunction with density functional theory for the structural assignment of the $\left[\mathrm{V}_{4} \mathrm{O}_{10}{ }^{-}, \mathrm{SO}_{2}\right]$ complex, revealing a square pyramidal structure with the $\mathrm{SO}_{2}$ molecule incorporated in the vanadium oxide framework. Energy profiles are calculated for the reaction between $\mathrm{V}_{4} \mathrm{O}_{10}{ }^{-}$and $\mathrm{V}_{6} \mathrm{O}_{15}{ }^{-}$with $\mathrm{SO}_{2}$. Whereas the transition structures along the reaction pathway of $\mathrm{V}_{4} \mathrm{O}_{10}{ }^{-}$with $\mathrm{SO}_{2}$ have energies below those of the separated partners, the reaction of $\mathrm{V}_{6} \mathrm{O}_{15}{ }^{-}$with $\mathrm{SO}_{2}$ proceeds via a transition structure with energy higher than the educts. The role of cluster size and composition is investigated by studying the reaction kinetics of larger $\left(\mathrm{V}_{6} \mathrm{O}_{15}{ }^{-}\right.$and $\left.\mathrm{V}_{8} \mathrm{O}_{20}{ }^{-}\right)$and titanium doped $\left(\mathrm{V}_{3} \mathrm{TiO}_{10}{ }^{-}\right.$and $\mathrm{V}_{2} \mathrm{Ti}_{2} \mathrm{O}_{10}{ }^{-}$) vanadium oxide clusters with $\mathrm{SO}_{2}$. The observed cluster size and composition dependencies are discussed.

\section{A Introduction}

Vanadium oxide has gained much attention as a catalyst over the past years. ${ }^{1}$ As an oxidative catalyst $\mathrm{V}_{2} \mathrm{O}_{5}$ has been used in various processes such as the oxidative dehydrogenation of propane, the formation of maleic anhydride from butane, the selective reduction of $\mathrm{NO}_{x}$ with ammonia, and the regeneration of petroleum refinery cracking catalysts. ${ }^{2}$ Also sulphur dioxide is oxidized to sulphur trioxide in the presence of supported vanadium oxide particles. The formation of $\mathrm{SO}_{3}$ is a key step in the production of sulfuric acid, the most abundant industrially produced compound. ${ }^{3}$ For this purpose traditional platinum based catalysts are replaced by low cost $\mathrm{V}_{2} \mathrm{O}_{5}$ based systems.

The vanadium oxide catalyzed production of $\mathrm{SO}_{3}$ from $\mathrm{SO}_{2}$ in industrial reactors is optimal at elevated temperatures

${ }^{a}$ Laboratorium voor Vaste-Stoffysica en Magnetisme, KU Leuven,

Celestijnenlaan 200D, B-3001 Leuven, Belgium.

E-mail: ewald.janssens@fys.kuleuven.be

${ }^{b}$ Institut für Experimentalphysik, Freie Universität Berlin,

Arnimallee 14, D-14195 Berlin, Germany

${ }^{c}$ Institut für Chemie, Humboldt-Universität Berlin, Unter den Linden 6, D-10099 Berlin, Germany. E-mail: js@chemie.hu-berlin.de

${ }^{d}$ Fritz-Haber-Institut der Max-Planck-Gesellschaft, Faradayweg 4-6, D-14195 Berlin, Germany

$\dagger$ Present address: Institut für Oberflächenchemie und Katalyse, Universität Ulm, Albert-Einstein-Allee 47, D-89069 Ulm, Germany.

$\ddagger$ Present address: Fritz-Haber-Institut der Max-Planck-Gesellschaft, Faradayweg 4-6, D-14195 Berlin, Germany.
$(>700 \mathrm{~K})$ and involves several steps: the adsorption of $\mathrm{SO}_{2}$, the oxidation of $\mathrm{SO}_{2}$ followed by the release of $\mathrm{SO}_{3}$, and the reoxidation of the vanadium oxide particles. ${ }^{4}$

Despite the important industrial relevance of vanadium oxide particles, many microscopic details of their catalytic behaviour are still unknown. The identification of the active sites with surface characterization techniques is experimentally very challenging. In this respect experiments on gas phase clusters provide an appropriate environment to investigate the influence of composition, cluster size, charge and oxidation state on the reactivity. ${ }^{5}$

Gas phase ion-molecule reactivity studies on mass-selected vanadium oxide clusters have, among others, been performed by the Castleman group ${ }^{6,7}$ and by the Schwarz group ${ }^{8,9}$ and mainly focused on the interaction of vanadium oxide cluster ions with small hydrocarbons. It was found that the reaction pathways and reaction rates strongly depend on the cluster size and charge state, as well as on the oxidation states of the vanadium atoms. Li et al. probed the photo-induced oxygen transfer for ethane adsorbed on $\mathrm{V}_{4} \mathrm{O}_{11}{ }^{-}$under controlled conditions in an ion trap reactor. ${ }^{10}$ Zhao et al. studied hydrogen abstraction from $n$-butane on binary vanadium-silicon oxide cluster anions. ${ }^{11}$ Two combined experimental and theoretical studies characterized the structures of selected complexes composed of a vanadium oxide cluster and a hydrocarbon reactant. Fielicke et al. measured the infrared photodissociation 
spectra of the association complex of $\mathrm{V}_{2} \mathrm{O}_{5,6}{ }^{+}$with ethylene formed in the expansion of a laser vaporisation source. ${ }^{12}$ Wende et al. obtained structural information on the reaction products of $\mathrm{V}_{4} \mathrm{O}_{10}{ }^{+}$with propane in a buffer gas filled ion trap. $^{13}$

Some spectrometric work has been done on the reaction of vanadium oxide clusters with $\mathrm{SO}_{2}$. Wyrwas studied the interaction of small anionic vanadium oxide clusters in a fast flow reactor as a function of the $\mathrm{SO}_{2}$ concentration. ${ }^{14}$ Incompletely oxidized vanadium clusters were proven to be more reactive than clusters with all vanadium atoms in the formal $+\mathrm{v}$ oxidation state. However, no quantitative conclusion could be drawn since also molecular oxygen was present in the flow reactor. Bernstein et al. studied the reactions of small neutral vanadium oxide clusters with $\mathrm{SO}_{2}$ in a fast-flow reactor by time-of-flight mass spectrometry and ultraviolet postionization in combination with density functional theory (DFT) calculations. ${ }^{15,16}$ They found indications for the formation of $\mathrm{SO}_{3}$ on oxygen-rich clusters. Other groups investigated the scattering behaviour of vanadium oxide cluster cations by $\mathrm{SO}_{2}$, but no special size dependencies were observed. ${ }^{17}$

To fully understand the correlation between cluster structure and reactivity, prior knowledge of the structure of the cluster is indispensable. This information has been gathered on cationic and anionic vanadium oxide clusters by combined vibrational spectroscopy experiments and DFT investigations. ${ }^{19-24}$ In particular, it was shown that the anionic $\left(\mathrm{V}_{2} \mathrm{O}_{5}\right)_{n}{ }^{-}(n=2-4)$ clusters have high symmetric polyhedral caged structures with $\operatorname{vanadyl}(\mathrm{V}=\mathrm{O})$ units at the apexes and oxygen atoms bridging the vanadium atoms $(\mathrm{V}-\mathrm{O}-\mathrm{V}) .{ }^{18}$ In addition, it was demonstrated that the vanadium atoms in $\mathrm{V}_{4} \mathrm{O}_{10}{ }^{-}$can be substituted by titanium atoms without significant distortion of the tetrahedral caged geometry. ${ }^{25}$ Also, the electronic structure of small vanadium oxide clusters was studied with anion photoelectron spectroscopy. ${ }^{26}$

Here we investigate the reaction kinetics of thermalized vanadium oxide and vanadium-titanium oxide cluster anions under multi-collision conditions as a function of the cluster temperature and $\mathrm{SO}_{2}$ partial pressure. In Section $\mathrm{B}$ the experimental method, the data analysis, and the theoretical method are presented. In Section $\mathrm{C}$ the interaction of $\mathrm{V}_{4} \mathrm{O}_{10}{ }^{-}$with $\mathrm{SO}_{2}$ is discussed in detail by investigating the structure of the $\left[\mathrm{V}_{4} \mathrm{O}_{10}, \mathrm{SO}_{2}\right]^{-}$complex and the associated reaction kinetics. In Section $\mathrm{D}$ the possible presence of high-energy transition structures in the reaction energy profile is discussed. Also the cluster size and cluster composition dependency are studied by comparing the reaction kinetics of $\mathrm{V}_{4} \mathrm{O}_{10}{ }^{-}$with that of $\mathrm{V}_{6} \mathrm{O}_{15}{ }^{-}, \mathrm{V}_{8} \mathrm{O}_{20}{ }^{-}, \mathrm{V}_{3} \mathrm{TiO}_{10}{ }^{-}$, and $\mathrm{V}_{2} \mathrm{Ti}_{2} \mathrm{O}_{10}{ }^{-}$.

\section{B Methods}

\section{B.1 Experimental setup}

The experiments to obtain temperature and pressure dependent rate constants were carried out in a tandem mass spectrometer-ion trap system, described in detail elsewhere. ${ }^{27}$

$\mathrm{V}_{m} \mathrm{Ti}_{n} \mathrm{O}_{o}{ }^{-}$clusters are produced by pulsed laser vaporization of the respective metal targets in the presence of $1 \% \mathrm{O}_{2}$ in
He using a $10 \mathrm{~Hz}$ dual laser vaporization source. ${ }^{28}$ The beam of negative ions is collimated and mass selection is achieved via a first quadrupole mass filter. Mass selected ions are accumulated in a linear radio-frequency ion trap. The trap is continuously filled with a small fraction of the reactant $\mathrm{SO}_{2}$ $(0.002-0.1 \%)$ in $\mathrm{He}$ at a total pressure of 4-9 $\mathrm{Pa}$ using a mass flow controller. Temperature control inside the trap between $20 \mathrm{~K}$ and $300 \mathrm{~K}$ is achieved with a helium cryostat attached to the trap enclosure. The absolute pressure in the trap is measured with a capacitance manometer (MKS, Baratron) having an accuracy of $0.01 \mathrm{~Pa}$. Since the $\mathrm{SO}_{2}$ vapour pressure at the lowest investigated temperature of $150 \mathrm{~K}$ is about $1 \mathrm{~Pa}$ and thus much higher than the partial $\mathrm{SO}_{2}$ pressure used in the experiments, a significant error on the $\mathrm{SO}_{2}$ concentration due to freezing can be excluded. The uncertainty in the composition of the diluted gas mixture, however, yields a typical uncertainty in the $\mathrm{SO}_{2}$ partial pressure of $20-30 \%$, which is the main factor for the uncertainty in the rate constants.

The applied pressures ensure multi-collision conditions in the low pressure regime of chemical kinetics and provide thermalisation, of both reactants and reaction products, within a few milliseconds. ${ }^{29}$ This thermalisation time is one to three orders of magnitude smaller than typical ion storage times inside the ion trap. After a defined storage time (reaction time $t_{\mathrm{R}}$ ) all ionic reactants, intermediates, and products are extracted from the trap and mass analyzed by a second quadrupole mass filter. Recording the different ion yields as a function of $t_{\mathrm{R}}$ gives time resolved kinetic measurements at a given cluster temperature and $\mathrm{SO}_{2}$ partial pressure.

The infrared multiple photon dissociation (IRMPD) spectrum of the $\left[\mathrm{V}_{4} \mathrm{O}_{10}, \mathrm{SO}_{2}\right]^{-}$complex is obtained on the same instrument by photoexcitation of the trapped ions with pulsed infrared radiation from the Free Electron Laser for Infrared eXpertiments (FELIX) located at the FOM Institute Rijnhuizen in the Netherlands. ${ }^{30}$ The method applied to measure IRMPD spectra has been described elsewhere. ${ }^{22}$ The ion trap is filled with mass selected $\mathrm{V}_{4} \mathrm{O}_{10}{ }^{-}$ions, which are thermalised at $125 \mathrm{~K}$ by inelastic collisions with the He buffer gas and reacted with the $\mathrm{SO}_{2}$ molecules present. FELIX is operated at $5 \mathrm{~Hz}$ and applied collinear to the ion trap main axis. Directly after FELIX fires all ions are extracted from the trap and detected mass-selectively. The IRMPD spectrum is recorded by monitoring the fragment ion intensity $\left(\mathrm{V}_{4} \mathrm{O}_{10}{ }^{-}\right)$. Photoabsorption manifests itself either as maxima in the fragment intensity or as dips in the $\left[\mathrm{V}_{4} \mathrm{O}_{10}, \mathrm{SO}_{2}\right]^{-}$complex ion signal. Spectra measured by recording the $\mathrm{V}_{4} \mathrm{O}_{10}{ }^{-}$fragment intensity indeed show the same spectral features as the $\left[\mathrm{V}_{4} \mathrm{O}_{10}, \mathrm{SO}_{2}\right]^{-}$complex ion signal. The IR spectrum is recorded in the $570-1100 \mathrm{~cm}^{-1}$ $(17.5-9.0 \mu \mathrm{m})$ range with a $0.02 \mu \mathrm{m}$ step size.

\section{B.2 Analysis of the kinetic traces}

The data evaluation procedure to analyze the temperature dependent kinetic traces and the corresponding error analysis is described in detail elsewhere ${ }^{29,31}$ and is only briefly summarized here. The normalized kinetic traces are evaluated by fitting the integrated rate equations of proposed reaction mechanisms to the experimental data using the 'Detmech' software. ${ }^{32}$ This leads to the determination of the simplest 
reaction mechanism that fits the experimental data best. The $\mathrm{SO}_{2}\left(\sim 10^{11} \mathrm{~cm}^{-3}\right)$ and $\mathrm{He}\left(\sim 10^{15} \mathrm{~cm}^{-3}\right)$ concentrations are several orders of magnitude larger than the cluster ion concentration $\left(\sim 10^{6} \mathrm{~cm}^{-3}\right)$ and therefore can be considered constant. Moreover, a continuous inflow of the reaction gas is ensured by the mass flow controller. Thus, the resulting rate constants are pseudo-first order.

Furthermore, the experiments are performed at 4-9 $\mathrm{Pa}$ of total pressure and thus in the kinetic low pressure regime. Consequently, each simple association reaction

$$
\mathrm{V}_{m} \mathrm{Ti}_{n} \mathrm{O}_{o}^{-}+\mathrm{SO}_{2} \rightarrow\left[\mathrm{V}_{m} \mathrm{Ti}_{n} \mathrm{O}_{o}, \mathrm{SO}_{2}\right]^{-} k_{\mathrm{f}}
$$

can be described by the Lindemann energy transfer model for association reactions: ${ }^{33}$

$$
\begin{array}{r}
\mathrm{V}_{m} \mathrm{Ti}_{n} \mathrm{O}_{o}^{-}+\mathrm{SO}_{2} \rightleftarrows\left[\mathrm{V}_{m} \mathrm{Ti}_{n} \mathrm{O}_{o}, \mathrm{SO}_{2}\right]^{-*} k_{\mathrm{a}}, k_{\mathrm{d}}(2 \mathrm{a}) \\
{\left[\mathrm{V}_{m} \mathrm{Ti}_{n} \mathrm{O}_{o}, \mathrm{SO}_{2}\right]^{-*}+\mathrm{He} \rightarrow\left[\mathrm{V}_{m} \mathrm{Ti}_{n} \mathrm{O}_{o}, \mathrm{SO}_{2}\right]^{-}+\mathrm{He}^{*} k_{\mathrm{s}}}
\end{array}
$$

According to this mechanism, the anionic metal oxide cluster reacts with $\mathrm{SO}_{2}$, resulting in the formation of an energized intermediate $\left[\mathrm{V}_{m} \mathrm{Ti}_{n} \mathrm{O}_{o}, \mathrm{SO}_{2}\right]^{-*}$ with a rate constant $k_{\mathrm{a}}$. This intermediate may decompose back to the reactants (rate constant $k_{\mathrm{d}}$ ) via unimolecular decay or may be stabilized by an energy-transfer collision with $\mathrm{He}$ (rate constant $k_{\mathrm{s}}$ ). Consequently, the overall forward reaction depends on the $\mathrm{He}$ buffer gas and is of third order. In the kinetic low pressure limit, the corresponding measured pseudo-first order rate constant $k_{\mathrm{f}}^{(1)}$ is given by: ${ }^{31,33}$

$$
k_{\mathrm{f}}=k_{\mathrm{f}}^{(1)}=k_{\mathrm{f}}^{(3)}\left[\mathrm{SO}_{2}\right][\mathrm{He}]=\left(k_{\mathrm{a}} k_{\mathrm{s}} / k_{\mathrm{d}}\right)\left[\mathrm{SO}_{2}\right][\mathrm{He}]
$$

The ion-molecule association rate constant $k_{\mathrm{a}}$ as well as the stabilization rate constant $k_{\mathrm{s}}$ are well represented by ionmolecule collision rate constants as specified by Langevin theory. ${ }^{34} k_{\mathrm{s}}$ only depends on the reduced mass of the $\left[\mathrm{V}_{m} \mathrm{Ti}_{n} \mathrm{O}_{o}\right.$, $\left.\mathrm{SO}_{2}\right]^{-*}-\mathrm{He}$ 'scattering complex' as well as the polarizability of the He atom $\left(\alpha=0.208 \AA^{3}\right)^{35}$ and is temperature independent. $\mathrm{SO}_{2}$ is a polar molecule with a permanent dipole moment $\mu_{\mathrm{D}}=5.4410^{-30} \mathrm{Cm}$ and a polarizability $\alpha=3.72 \AA^{3} \cdot{ }^{35,36}$ To estimate $k_{\mathrm{a}}$, the Langevin rate constant was corrected by a slightly temperature dependent empirical expression found by $\mathrm{Su}^{37}$ The resulting temperature dependence of $k_{\mathrm{a}}$ is much smaller than the experimentally observed temperature dependence of $k_{\mathrm{f}}$, which consequently must be contained in the unimolecular decomposition rate constant $k_{\mathrm{d}}$.

Applying eqn (2) and (3) allows for the determination of an experimental unimolecular decomposition rate constant $k_{\mathrm{d}}$ which might also be described by RRKM (Rice-RamspergerKassel-Marcus) theory. ${ }^{38,39}$ This theory is usually applied to determine $k_{\mathrm{d}}$ from the known binding energy of the ligand to the cluster ion. In our experimental approach $k_{\mathrm{d}}$ is the quantity derived from the experimental data, which consequently allows for the determination of the $\mathrm{SO}_{2}$ binding energy. In order to obtain RRKM binding energies $E_{0}, k_{\mathrm{d}}$ was simulated using the 'MassKinetics' software package. ${ }^{40}$

\section{B.3 Theoretical methods}

DFT calculations on $\left[\mathrm{V}_{4} \mathrm{O}_{10}, \mathrm{SO}_{2}\right]^{-}$were performed using the TURBOMOLE program. ${ }^{41}$ The B3LYP hybrid functional ${ }^{42}$ is employed in conjunction with the triple-zeta valence basis sets developed by Ahlrichs and coworkers ${ }^{43}$ and augmented by polarization functions: a d-set for oxygen and a p-set for vanadium. ${ }^{44}$ Since sulphur requires tight d-functions, ${ }^{45}$ the $3 \mathrm{~d}$ function of the TZVP set for sulphur (0.550) has been replaced by the two $d$ functions $(2.994 ; 0.481)$ of the cc-pV(D $+d) Z$ basis set. $^{46}$

Initial guesses for transition structures were obtained from scans of appropriate internal coordinates. Starting from those structures the eigenvector following method was applied as implemented in TURBOMOLE. Stationary points found were characterized by harmonic frequency calculations, yielding one imaginary frequency for transition structures. To confirm that an obtained transition structure connects specific minima, this structure was distorted along the imaginary frequency mode in both directions.

Harmonic vibrational frequencies are obtained from second analytic derivatives. ${ }^{47}$ To account for both anharmonicities and systematic errors of the calculated harmonic force constants, the computed vibrational frequencies are scaled using scaling factors consistent with our earlier work. ${ }^{20,22,48} \mathrm{~A}$ different scale factor is used for $\mathrm{V}=\mathrm{O}$ vanadyl modes (0.9167) and V-O-V and other modes (0.9832). The calculated $\mathrm{S}=\mathrm{O}$ stretching frequencies are scaled by a factor of 1.0206 as derived by comparing the $\mathrm{B} 3 \mathrm{LYP} / \mathrm{TZVP}+\mathrm{d}$ frequencies of $\mathrm{SO}_{2}\left(1322\right.$ and $\left.1139 \mathrm{~cm}^{-1}\right)$ with the experimental values (1362 and $\left.1151 \mathrm{~cm}^{-1}\right){ }^{49}$

\section{The reaction of $\mathrm{V}_{4} \mathrm{O}_{10}{ }^{-}$with $\mathrm{SO}_{2}$}

The reaction of $\mathrm{V}_{4} \mathrm{O}_{10}{ }^{-}$with $\mathrm{SO}_{2}$ is chosen as a model system to gain insight into the $\mathrm{SO}_{2}$ bonding mechanism. First the structure of the $\left[\mathrm{V}_{4} \mathrm{O}_{10}, \mathrm{SO}_{2}\right]^{-}$complex is assigned using IRMPD spectroscopy in conjunction with DFT calculations. Then the reaction energy profile is discussed. It is shown computationally that the adsorption of $\mathrm{SO}_{2}$ on $\mathrm{V}_{4} \mathrm{O}_{10}{ }^{-}$is a barrierless process. Thereafter, the temperature dependent reaction kinetics is presented and finally the experimental $\mathrm{SO}_{2}$ binding energy is derived employing the Lindemann energy transfer mechanism for association reactions in conjunction with RRKM theory.

\section{C.1 Structural assignment of $\left[\mathrm{V}_{4} \mathrm{O}_{10}, \mathrm{SO}_{2}\right]^{-}$}

The experimental IRMPD spectrum of $\left[\mathrm{V}_{4} \mathrm{O}_{10}, \mathrm{SO}_{2}\right]^{-}$, shown in Fig. 1 (bottom trace), exhibits an intensive absorption band at $1003 \mathrm{~cm}^{-1}$ with two shoulder peaks on its high energy side at 1029 and $1046 \mathrm{~cm}^{-1}$. In the $700-950 \mathrm{~cm}^{-1}$ range there are five distinct absorption bands (at 742, 799, 825, 870, and $900 \mathrm{~cm}^{-1}$ ).

The IRMPD spectrum of $\left[\mathrm{V}_{4} \mathrm{O}_{10}, \mathrm{SO}_{2}\right]^{-}$strikingly differs from that of the bare $\mathrm{V}_{4} \mathrm{O}_{10}{ }^{-}$cluster, which is dominated by a single intense vanadyl band at $990 \mathrm{~cm}^{-1}$ and has some weaker absorptions around $600-650 \mathrm{~cm}^{-1} \cdot{ }^{18,22}$ The simplicity of the $\mathrm{V}_{4} \mathrm{O}_{10}{ }^{-}$IRMPD spectrum is due to its high symmetric tetragonal $D_{2 \mathrm{~d}}$ structure with the unpaired electron being completely delocalized over the d-states of the four vanadium atoms. Localisation of the unpaired electron at a single vanadium site lowers the symmetry and leads to intense $\mathrm{V}-\mathrm{O}-\mathrm{V}$ stretches in the $800-1000 \mathrm{~cm}^{-1}$ range. ${ }^{18}$ Based on this knowledge the 


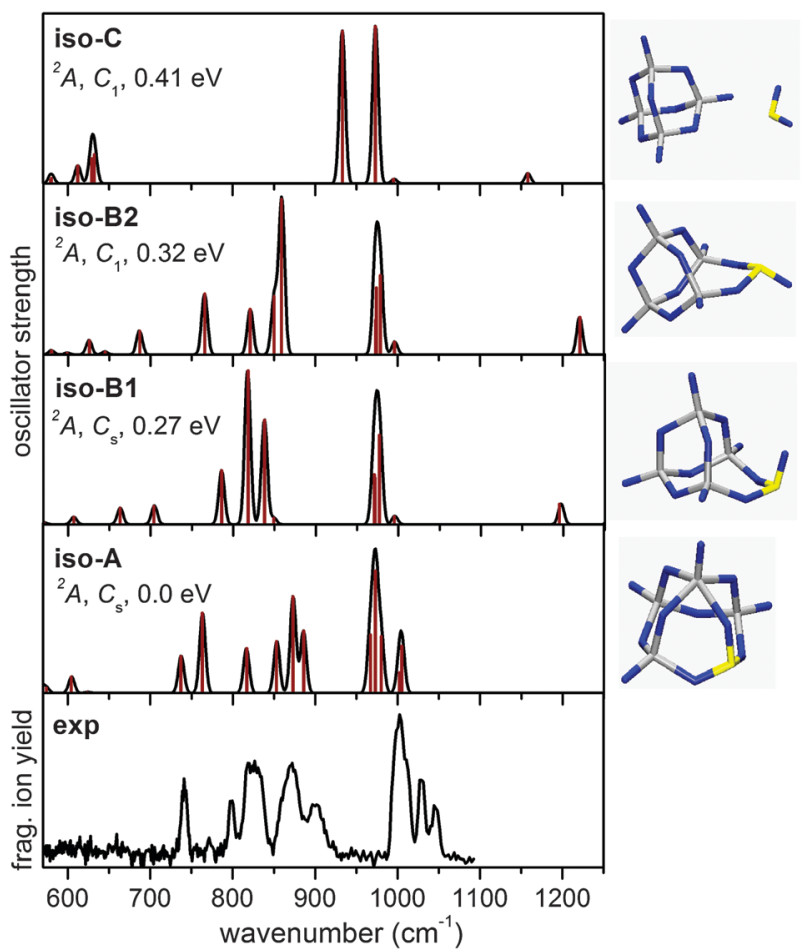

Fig. 1 (Bottom) IRMPD spectrum of $\left[\mathrm{V}_{4} \mathrm{O}_{10}, \mathrm{SO}_{2}\right]^{-}$, measured by recording the $\mathrm{V}_{4} \mathrm{O}_{10}{ }^{-}$fragment intensity in the $570-1100 \mathrm{~cm}^{-1}$ range. (Top) Simulated linear IR absorption spectra, based on scaled $\mathrm{B} 3 \mathrm{LYP} / \mathrm{TZVP}+\mathrm{d}$ frequencies and oscillator strengths of four low energy $\left[\mathrm{V}_{4} \mathrm{O}_{10}, \mathrm{SO}_{2}\right]^{-}$isomers. The corresponding structures of the $\left[\mathrm{V}_{4} \mathrm{O}_{10}, \mathrm{SO}_{2}\right]^{-}$isomers are shown on the right (O blue, $\mathrm{V}$ grey, and $\mathrm{S}$ yellow).

experimental IRMPD spectrum of $\left[\mathrm{V}_{4} \mathrm{O}_{10}, \mathrm{SO}_{2}\right]^{-}$can be interpreted as follows: (i) the absorptions in the $1000-1050 \mathrm{~cm}^{-1}$ range correspond to vanadyl modes. The presence of multiple bands in this range suggests that, differently from $\mathrm{V}_{4} \mathrm{O}_{10}{ }^{-}$, the symmetry of the structure is broken. (ii) The absorptions in the $750-950 \mathrm{~cm}^{-1}$ range correspond to $\mathrm{V}-\mathrm{O}-\mathrm{V}$ modes (possibly also $\mathrm{V}-\mathrm{O}-\mathrm{S}$ modes) and the unpaired electron is localized in a vanadium $d$ state. This interpretation is confirmed by the results of DFT calculations, which also yield specific structure information.

Simulated linear absorption spectra of four structural isomers predicted by DFT, labeled A, B1, B2, and $\mathbf{C}$, are plotted in Fig. 1. The obtained global energetic minimum, A $\left(C_{\mathrm{s}}, 0 \mathrm{eV}\right)$, is a pentameric cluster with a square pyramidal structure resembling the structure of $\mathrm{V}_{5} \mathrm{O}_{13}{ }^{-}\left(C_{4 \mathrm{v}}\right){ }^{22}$ Structures in which $\mathrm{SO}_{2}$ bridges two $\mathrm{OV}(\mathrm{O}-)_{3}$ units, $\mathbf{B} 1\left(C_{\mathrm{s}},+0.27 \mathrm{eV}\right)$ and B2 $\left(C_{1},+0.32 \mathrm{eV}\right)$ can be derived from the bridged $C_{2 \mathrm{v}}$ structure of $\mathrm{V}_{5} \mathrm{O}_{13}{ }^{-}\left(C_{2 \mathrm{v}}\right)^{22}$ when replacing the $(\mathrm{O}=)_{2} \mathrm{~V}^{(-)}(-\mathrm{O})_{2}$ unit by $(\mathrm{O}=) \mathrm{S}(-\mathrm{O})_{2}$ and putting an unpaired electron in a d-state of one of the vanadium sites. The $\mathrm{V}_{4} \mathrm{O}_{10}{ }^{-} \cdot \mathrm{SO}_{2}$ encounter complex, $\mathbf{C}\left(C_{1}, 0.41 \mathrm{eV}\right)$, is significantly less stable. Comparison with the IRMPD spectrum indeed shows that the encounter complex is not present in the experiment.

The pyramidal global minimum structure, $\mathbf{A}$, is the only isomer without $\mathrm{S}=\mathrm{O}$ vibrations at wavenumbers above the $\mathrm{V}=\mathrm{O}$ region. The other isomers have short $\mathrm{S}=\mathrm{O}$ bonds (146-147 pm) with predicted wavenumbers $\left(1173-1196 \mathrm{~cm}^{-1}\right)$ well above the $\mathrm{V}=\mathrm{O}$ region $\left(1059-1087 \mathrm{~cm}^{-1}\right)$. The IR spectrum of isomer $A$ resembles that of $\mathrm{V}_{5} \mathrm{O}_{13}{ }^{-}$[ref. 22] and agrees best with the experimental IRMPD spectrum of $\left[\mathrm{V}_{4} \mathrm{O}_{10}, \mathrm{SO}_{2}\right]^{-}$. In comparison to $\mathrm{V}_{5} \mathrm{O}_{13}{ }^{-}$, one of the $\mathrm{O}=\mathrm{VO}_{3 / 2}$ corners of the square has been replaced by $\mathrm{S}^{(+)} \mathrm{O}_{3 / 2}$, and the $\mathrm{O}=\mathrm{V}\left(\mathrm{d}^{0}\right)^{(-)} \mathrm{O}_{4 / 2}$ top site has been replaced by a $\mathrm{O}=\mathrm{V}\left(\mathrm{d}^{1}\right)^{(2-)} \mathrm{O}_{4 / 2}$ site with the unpaired electron localized in the d-states of this vanadium atom, in line with the intuitive interpretation given above. In the $1000-1050 \mathrm{~cm}^{-1}$ region, the experimental spectrum seems to have more features (three peaks plus one shoulder) than the simulated spectrum for $\mathbf{A}$ (two peaks). However, the calculation yields four different vanadyl stretching frequencies, and the DFT calculation may underestimate the energy differences between the four modes. Although the existence of another minimum with similar energy can never be excluded, we feel that for this level of agreement there is no need for applying a global optimization technique such as a genetic algorithm. We note, however, that based on the comparison with the IRMPD spectrum, the presence of (a minor fraction of) isomers $\mathbf{B} 1$ and $\mathbf{B 2}$ in the ion trap cannot be excluded.

\section{C.2 DFT energy profile for the reaction of $\mathrm{V}_{4} \mathrm{O}_{10}{ }^{-}$with $\mathrm{SO}_{2}$}

The energy profile for the reaction from the educts $\mathrm{V}_{4} \mathrm{O}_{10}{ }^{-}$and $\mathrm{SO}_{2}$ to the final product, $\mathrm{A}$, has been calculated by DFT. Upon collision of $\mathrm{V}_{4} \mathrm{O}_{10}{ }^{-}$with $\mathrm{SO}_{2}$, the encounter complex $\mathbf{C}$ is formed, which is separated from the "bridging" isomer B1 by a small barrier, TS1. The energy of this transition structure is $0.09 \mathrm{eV}$ below that of the separated $\mathrm{V}_{4} \mathrm{O}_{10}{ }^{-}$and $\mathrm{SO}_{2}$. Note that (at least at this computational level) $\mathbf{B} 1$ is not directly reached from TS1, but there is an extremely shallow intermediate that has almost the same energy as the second transition structure TS2. B1 further transforms into the square pyramidal ground-state structure, $\mathbf{A}$. The $\mathrm{SO}_{2}$ binding energy in $\mathbf{A}$ is $0.70 \mathrm{eV}$.

\section{C.3 Temperature dependent reaction kinetics}

Fig. 3(a) displays, as an example, an anion mass distribution obtained after storing $\mathrm{V}_{4} \mathrm{O}_{10}{ }^{-}$in the presence of $\mathrm{SO}_{2}\left(p\left(\mathrm{SO}_{2}\right)=\right.$ $\left.(4.4 \pm 1.1) \times 10^{-3} \mathrm{~Pa}\right)$ in the ion trap at $T_{\mathrm{R}}=225 \mathrm{~K}$. The kinetic traces in Fig. 3(b)-(d) show the normalized product ion concentrations (open symbols) as a function of reaction time $t_{\mathrm{R}}$ for different reaction temperatures and $\mathrm{SO}_{2}$ partial pressures. Independent of the reaction temperature $(275-150 \mathrm{~K})$, $\mathrm{V}_{4} \mathrm{O}_{10}{ }^{-}$adsorbs a single $\mathrm{SO}_{2}$ molecule, forming exclusively $\left[\mathrm{V}_{4} \mathrm{O}_{10}, \mathrm{SO}_{2}\right]^{-}$. At the highest investigated temperatures $(275 \mathrm{~K}$ and $250 \mathrm{~K})$ the reaction is best described by an equilibrium reaction mechanism according to

$$
\mathrm{V}_{4} \mathrm{O}_{10}{ }^{-}+\mathrm{SO}_{2} \rightleftarrows\left[\mathrm{V}_{4} \mathrm{O}_{10}, \mathrm{SO}_{2}\right]^{-} k_{\mathrm{f}}, k_{\mathrm{b}}
$$

while at lower temperatures the backreaction $k_{\mathrm{b}}$ is hampered and becomes up to two orders of magnitude smaller than $k_{\mathrm{f}}$. This positive temperature dependence is in line with the Lindemann mechanism ${ }^{33}$ that has to be considered to describe the details of the backward reaction step. The solid lines in Fig. 3(b)-(d) are obtained by fitting the integrated rate equations of this proposed reaction mechanism to the experimental kinetic data. 
Table 1 Measured termolecular $k_{\mathrm{f}}^{(3)}$ rate constants for the forward reaction between $\mathrm{V}_{4} \mathrm{O}_{10}{ }^{-}$and $\mathrm{SO}_{2}$ and corresponding unimolecular decomposition rate constant $k_{\mathrm{d}}$ of the energized complex as function of the reaction temperature $T_{\mathrm{R}}$

\begin{tabular}{lcc}
\hline$T_{\mathrm{R}} / \mathrm{K}$ & $k_{\mathrm{f}}^{(3) a} / 10^{-28} \mathrm{~cm}^{6} \mathrm{~s}^{-1}$ & $k_{\mathrm{d}}{ }^{a} / 10^{9} \mathrm{~s}^{-1}$ \\
\hline 150 & $5.4 \pm 2.0$ & $1.7 \pm 0.6$ \\
175 & $3.2 \pm 1.2$ & $2.6 \pm 1.0$ \\
200 & $1.8 \pm 0.7$ & $4.4 \pm 1.7$ \\
225 & $0.75 \pm 0.24$ & $9.9 \pm 3.2$ \\
250 & $0.73 \pm 0.14$ & $10 \pm 2$ \\
275 & $1.2 \pm 0.4$ & $5.9 \pm 2.1$
\end{tabular}

${ }^{a}$ The uncertainty in $k_{\mathrm{f}}{ }^{(3)}$ and $k_{\mathrm{d}}$ results from the fitting procedure as well as the uncertainty in the partial $\mathrm{He}$ and $\mathrm{SO}_{2}$ pressure.

The temperature dependent termolecular rate constants $k_{\mathrm{f}}^{(3)}$ and the unimolecular decomposition rate constants $k_{\mathrm{d}}$ are summarized in Table 1. From this table it is apparent that $k_{\mathrm{f}}^{(3)}$ decreases and $k_{\mathrm{d}}$ increases with increasing temperature. These temperature dependences are typical for ion-molecule reactions, ${ }^{33,50}$ and can be explained in terms of the abovedescribed energy transfer model for association reactions (cf. Section B.2) The unimolecular decomposition involves an activation barrier associated with the activation and cleavage of the $\mathrm{V}_{4} \mathrm{O}_{10}{ }^{-}-\mathrm{SO}_{2}$ bond, yielding a negative and positive temperature dependence for $k_{\mathrm{f}}^{(3)}$ and $k_{\mathrm{d}}$, respectively. Usually, this indicates a barrier-free interaction of $\mathrm{V}_{4} \mathrm{O}_{10}{ }^{-}$with $\mathrm{SO}_{2}$.

The recorded $\left[\mathrm{V}_{4} \mathrm{O}_{10}, \mathrm{SO}_{2}\right]^{-}$signal does not represent the simple encounter complex $\mathbf{C}$ but instead a pyramidal structure (isomer A) is formed even at temperatures as low as $125 \mathrm{~K}$ (cf. Section C.1), which involves two activation barriers (cf. Fig. 2). The energy gained upon formation of the encounter complex $\mathbf{C}$, which represents the first reaction step, is larger than the energy barriers associated with the transition states TS1 and TS3 (cf. Fig. 2). Consequently, there is always enough energy in the cluster complex available to overcome these activation barriers independent of the reaction temperature and the rate of stabilization $k_{\mathrm{s}}(c f$. eqn (2b)). Thus, the barriers are not reflected in the experimental kinetic data. The experimental kinetics appear similar to those resulting in

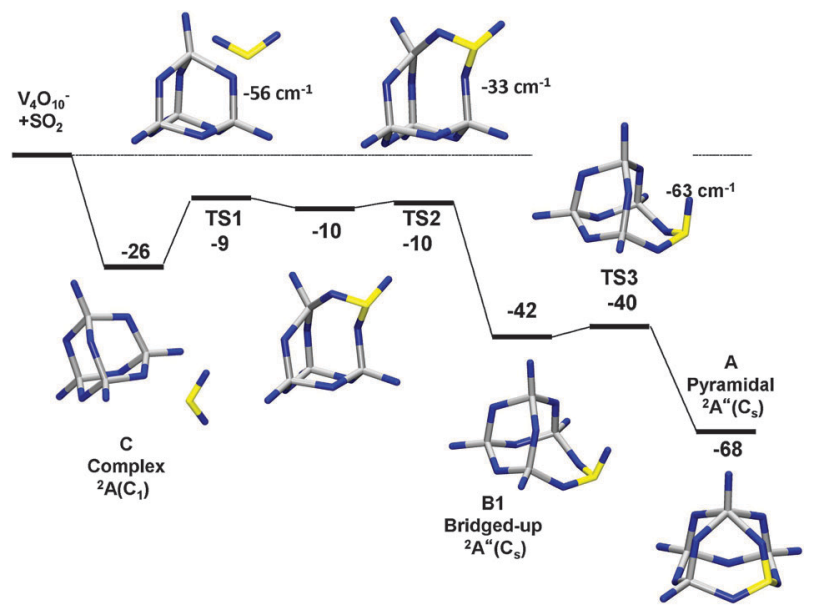

Fig. 2 DFT reaction energy profile for the formation of $\mathbf{A}$ for $\left[\mathrm{V}_{4} \mathrm{O}_{10}\right.$, $\left.\mathrm{SO}_{2}\right]^{-}$from $\mathrm{V}_{4} \mathrm{O}_{10}{ }^{-}$and $\mathrm{SO}_{2}$. Relative energies are given in $\mathrm{kJ} \mathrm{mol}^{-1}$. For transition structures, the imaginary mode frequencies are also given.
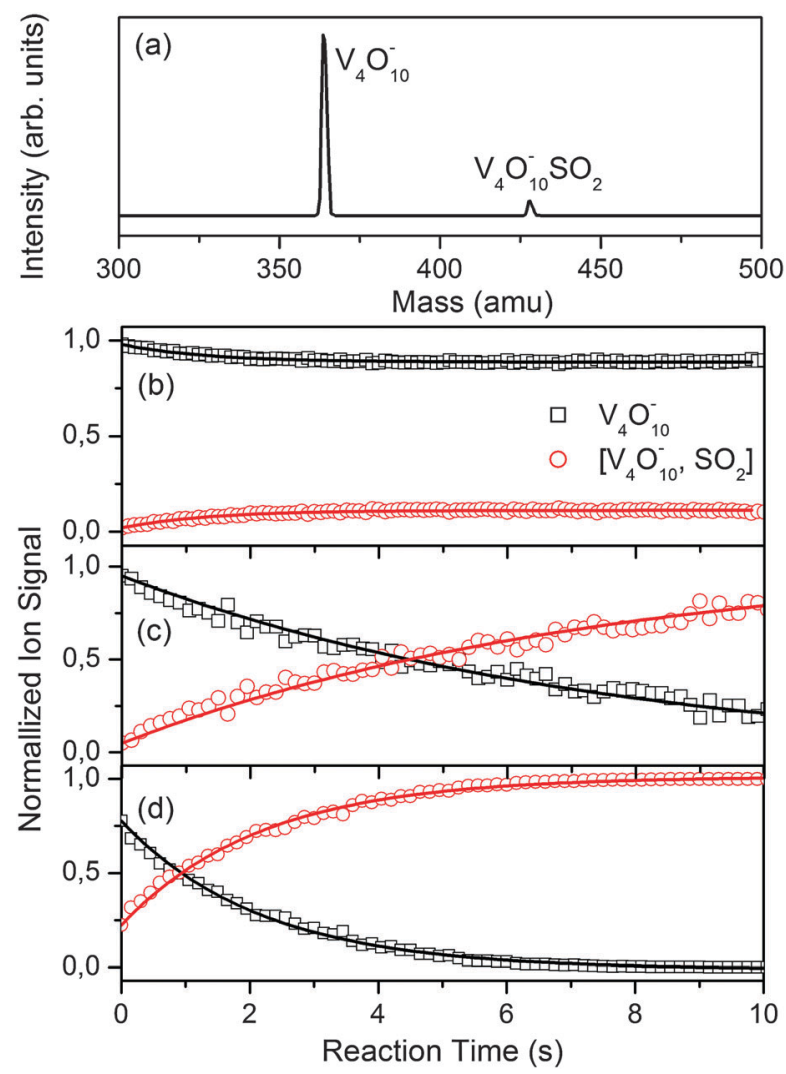

Fig. 3 (a) Mass spectrum of $\mathrm{V}_{4} \mathrm{O}_{10}{ }^{-}$after reaction with $(4.4 \pm 1.1) \times$ $10^{-3} \mathrm{~Pa} \mathrm{SO}_{2}$ for $t_{\mathrm{R}}=400 \mathrm{~ms}$ at $T_{\mathrm{R}}=225 \mathrm{~K}$. (b)-(d) Selected kinetic data of the reaction of $\mathrm{V}_{4} \mathrm{O}_{10}{ }^{-}$with $\mathrm{SO}_{2}$ at (b) $T_{\mathrm{R}}=275 \mathrm{~K}$ and $p\left(\mathrm{SO}_{2}\right)=(2.3 \pm 0.3) \times 10^{-3} \mathrm{~Pa}$, (c) $T_{\mathrm{R}}=225 \mathrm{~K}$ and $p\left(\mathrm{SO}_{2}\right)=$ $(4.4 \pm 1.1) \times 10^{-3} \mathrm{~Pa}$, and (d) $T_{\mathrm{R}}=150 \mathrm{~K}$ and $p\left(\mathrm{SO}_{2}\right)=(6 \pm 2) \times$ $10^{-4} \mathrm{~Pa}$. Open symbols represent the normalized intensities; solid lines are obtained by fitting with the integrated rate equations corresponding to eqn (4). Rate constants are given in Table 1.

the barrier-free formation of an encounter complex and the inverse reaction, i.e. the decomposition of isomer $\mathbf{A}$, can be described by statistical unimolecular decay theories such as RRKM.

The determination of cluster-molecule binding energies employing RRKM theory has been described in detail before $^{31,50}$ and is only briefly outlined here. For the energized complex we used the computed frequencies of the $\left[\mathrm{V}_{4} \mathrm{O}_{10}\right.$, $\left.\mathrm{SO}_{2}\right]^{-}$ground state structure (iso-A), while the 'loose' TS model is employed. The 'loose' TS is suitable to model simple bond cleavage reactions but was also shown to be a most realistic model for more complex processes, such as those occurring in the dissociation of bare metal clusters. ${ }^{51}$ For this TS model eight vibrations with large $\mathrm{SO}_{2}$ contribution were selected and scaled by a factor $f=0.5$ in addition to the removal of one mode $\left(\mathrm{V}_{4} \mathrm{O}_{10}{ }^{-}-\mathrm{SO}_{2}\right.$ breathing mode with large amplitude on the $\mathrm{S}$ atom). ${ }^{31,50-52}$ Furthermore, adiabatic rotations were taken into account by considering a temperature dependent rotational barrier, $E_{\mathrm{RB}} \cdot{ }^{31,40}$ The resulting $\mathrm{V}_{4} \mathrm{O}_{10}{ }^{-}-\mathrm{SO}_{2}$ binding energy amounts to $E_{0}=0.72 \pm 0.12 \mathrm{eV}$. Despite the very simplified model for $\left[\mathrm{V}_{4} \mathrm{O}_{10}, \mathrm{SO}_{2}\right]^{-*}$ and the transition state and the rather complex theoretically predicted reaction pathway, the experimentally obtained binding energy is in 
excellent agreement with the computed binding energy of $0.70 \mathrm{eV}$ for $\mathbf{A}$. This demonstrates that not the exact frequencies of the energized complex and the transition state but the frequency distribution and in particular the temperature dependence of the decomposition rate constants determine the binding energy. ${ }^{31}$ To further demonstrate the insensitivity of the RRKM analysis on exact vibrational frequencies a second set of frequencies was employed. In this set the computed frequencies of the bare $\mathrm{V}_{4} \mathrm{O}_{10}{ }^{-}$cluster was used and the remaining frequencies were set equal to those of the free $\mathrm{SO}_{2}$ molecule, ${ }^{49}$ a cluster $-\mathrm{SO}_{2}$ stretching frequency of $880 \mathrm{~cm}^{-1}, 53,54$ and five low frequency bending modes of $50 \mathrm{~cm}^{-1} .{ }^{31}$ This second set of vibrational frequencies resulted in $E_{0}=0.69 \pm 0.08 \mathrm{eV}$, which falls well within the experimental uncertainty.

\section{D $\mathrm{SO}_{2}$ adsorption on $\mathrm{V}_{6} \mathrm{O}_{15}{ }^{-}, \mathrm{V}_{8} \mathrm{O}_{20}{ }^{-}, \mathrm{V}_{3} \mathrm{TiO}_{10}{ }^{-}$, and $\mathrm{V}_{2} \mathrm{Ti}_{\mathbf{2}} \mathrm{O}_{10}{ }^{-}$}

Clusters size and cluster composition affect the characteristics of the $\mathrm{SO}_{2}$ adsorption. The size dependency is investigated by considering the reaction kinetics of the $\mathrm{V}_{4} \mathrm{O}_{10}{ }^{-}, \mathrm{V}_{6} \mathrm{O}_{15}{ }^{-}$, $\mathrm{V}_{8} \mathrm{O}_{20}{ }^{-}$series. The influence of the electron configuration is studied by isomorphous substitution ${ }^{25}$ of vanadium by titanium along the $\mathrm{V}_{4} \mathrm{O}_{10}{ }^{-}, \mathrm{V}_{3} \mathrm{TiO}_{10}{ }^{-}, \mathrm{V}_{2} \mathrm{Ti}_{2} \mathrm{O}_{10}{ }^{-}$series. Before discussing the experimental reaction kinetic data, the energy profile of the reaction of $\mathrm{V}_{6} \mathrm{O}_{15}{ }^{-}$with $\mathrm{SO}_{2}$ is calculated by DFT. It is shown that in this case the final product can only be formed after passing a transition structure with an energy well above the ground state energy of the educts.

\section{D.1 DFT calculations of the energy profile for the reaction of $\mathrm{V}_{6} \mathrm{O}_{15}{ }^{-}$with $\mathrm{SO}_{2}$}

Using the same approach as for $\mathrm{V}_{4} \mathrm{O}_{10}$ (see Section C.2), the structures of different $\left[\mathrm{V}_{6} \mathrm{O}_{15}, \mathrm{SO}_{2}\right]^{-}$isomers have been calculated by DFT. Moreover, the reaction energy profile for the formation of $\left[\mathrm{V}_{6} \mathrm{O}_{15}, \mathrm{SO}_{2}\right]^{-}$from $\mathrm{V}_{6} \mathrm{O}_{15}{ }^{-}$and $\mathrm{SO}_{2}$ has been calculated (Fig. 4). Upon collision of $\mathrm{V}_{6} \mathrm{O}_{15}{ }^{-}$with $\mathrm{SO}_{2}$ a $\mathrm{V}_{6} \mathrm{O}_{15}{ }^{-} \cdot \mathrm{SO}_{2}$ encounter complex, $\mathrm{C}$, is formed. This encounter complex can only transform into a structure with $\mathrm{SO}_{2}$ incorporated into the vanadium oxide framework after passing a transition structure for the reorganization, TS1, which is predicted at $+0.55 \mathrm{eV}$ above the educts. Once this transition structure is formed, the structure of the $\left[\mathrm{V}_{6} \mathrm{O}_{15}, \mathrm{SO}_{2}\right]^{-}$system sequentially goes through isomer $\mathbf{B}^{\prime}, \mathbf{T S 2}$, isomer $\mathbf{B}$, and TS3 $(0.26 \mathrm{eV}, 0.21 \mathrm{eV}, 0.26 \mathrm{eV}$, and $0.26 \mathrm{eV}$, respectively, below the educts) to reach the most stable pyramidal isomer found in the present study, $\mathbf{A}$. In $\mathbf{A}$ the $\mathrm{SO}_{2}$ binding energy to $\mathrm{V}_{6} \mathrm{O}_{15}{ }^{-}$is $0.58 \mathrm{eV}$.

The structures of isomers $\mathbf{A}$ and $\mathbf{B}$ correspond to the pyramidal and bridging isomers of $\mathrm{V}_{7} \mathrm{O}_{18}{ }^{-22}$

The reaction energy profile of the reaction of $\mathrm{V}_{6} \mathrm{O}_{15}{ }^{-}$with $\mathrm{SO}_{2}$ is characterized by the transition state TS1 with an energy above that of the entrance channel. This implies that an activation step is needed to reach the transition state. According to the Lindemann energy transfer model for association reactions, the collision of $\mathrm{V}_{6} \mathrm{O}_{15}{ }^{-}$with $\mathrm{SO}_{2}$ first yields the energized complex $\left[\mathrm{V}_{6} \mathrm{O}_{15}, \mathrm{SO}_{2}\right]^{-*}$ ( $c f$. eqn (2a)). The potential energy gain upon formation of the encounter complex $\mathbf{C}$

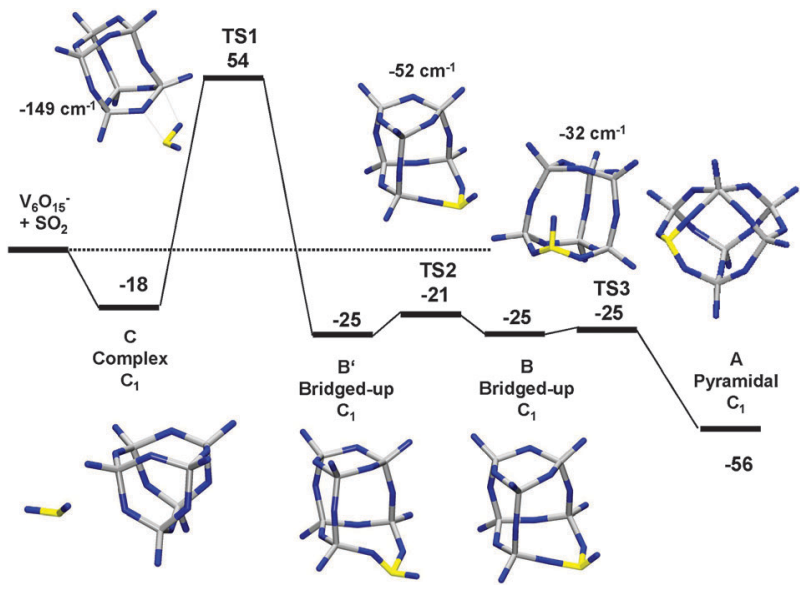

Fig. 4 DFT reaction energy profile for the formation of isomer $\mathbf{A}$ of $\left[\mathrm{V}_{6} \mathrm{O}_{15}, \mathrm{SO}_{2}\right]^{-}$from $\mathrm{V}_{6} \mathrm{O}_{15}{ }^{-}$and $\mathrm{SO}_{2}$. Relative energies are given in $\mathrm{kJ} \mathrm{mol}^{-1}$. For transition structures, the imaginary mode frequencies are also given.

amounts to $0.17 \mathrm{eV}$, equivalent to the $\mathrm{SO}_{2}$ binding energy. However, the experiments are performed in a temperature range of $250-175 \mathrm{~K}$, which means that the encounter complex contains additional energy, namely, vibrational energy of the reactants before reaction and energy contained in the translational and rotational degrees of freedom that is converted into internal energy upon reaction. Following a rough estimate as proposed by Cox et al. ${ }^{55}$ the total energy $E^{*}$ contained in the energized complex $\left[\mathrm{V}_{6} \mathrm{O}_{15}, \mathrm{SO}_{2}\right]^{-*}$ amounts to $1.08-1.47 \mathrm{eV}$ in the investigated temperature range. Thus, the energy barrier associated with TS1 of $0.75 \mathrm{eV}$ can be easily overcome and the minimum energy structure $\mathbf{A}$ is likely to be formed. Even in the case of a fast stabilization of $\left[\mathrm{V}_{6} \mathrm{O}_{15}, \mathrm{SO}_{2}\right]^{-*}$ by a $\mathrm{He}$ collision ( $c f$. eqn (2b)) the internal energy of the thermal complex $\left[\mathrm{V}_{6} \mathrm{O}_{15}, \mathrm{SO}_{2}\right]^{-}$is sufficient to cross the energy barrier.

As outlined in Section B.2 and eqn (2a), the energized complex $\left[\mathrm{V}_{6} \mathrm{O}_{15}, \mathrm{SO}_{2}\right]^{-*}$ can decompose unimolecularly back to the reactants with a rate constant $k_{\mathrm{d}}$. As demonstrated in Section C.3 for $\mathrm{V}_{4} \mathrm{O}_{10}{ }^{-}$, this rate constant can be used to determine experimental $\mathrm{SO}_{2}$ binding energies by applying RRKM theory. However, in the case of $\left[\mathrm{V}_{6} \mathrm{O}_{15}, \mathrm{SO}_{2}\right]^{-*}$ the decomposition rate constant is not determined by the activation barrier associated with the activation and cleavage of the $\mathrm{V}_{6} \mathrm{O}_{15}{ }^{-}-\mathrm{SO}_{2}$ bond, but instead by the considerably higher activation barrier associated with TS1. Due to this activation barrier the experimentally obtained $k_{\mathrm{d}}$ values decrease and an RRKM estimate of the binding energy would result in a too high value. Consequently, statistical RRKM theory cannot be applied to $\mathrm{V}_{6} \mathrm{O}_{15}{ }^{-}$to determine experimental binding energies due to the activation barrier that is higher than the energy of the educts.

\section{D.2 Reaction kinetics of $\mathrm{V}_{6} \mathrm{O}_{15}{ }^{-}, \mathrm{V}_{8} \mathrm{O}_{20}{ }^{-}, \mathrm{V}_{3} \mathrm{TiO}_{10}{ }^{-}$, and $\mathbf{V}_{\mathbf{2}} \mathrm{Ti}_{\mathbf{2}} \mathbf{O}_{\mathbf{1 0}}{ }^{-}$}

Fig. 5 displays selected ion mass distributions detected after storing $\mathrm{V}_{6} \mathrm{O}_{15}{ }^{-}, \mathrm{V}_{8} \mathrm{O}_{20}{ }^{-}, \mathrm{V}_{3} \mathrm{TiO}_{10}{ }^{-}$, and $\mathrm{V}_{2} \mathrm{Ti}_{2} \mathrm{O}_{10}{ }^{-}$in the ion trap in the presence of $\mathrm{SO}_{2}$. The gas-phase reactions of the clusters with $\mathrm{SO}_{2}$ are investigated at different ion trap 


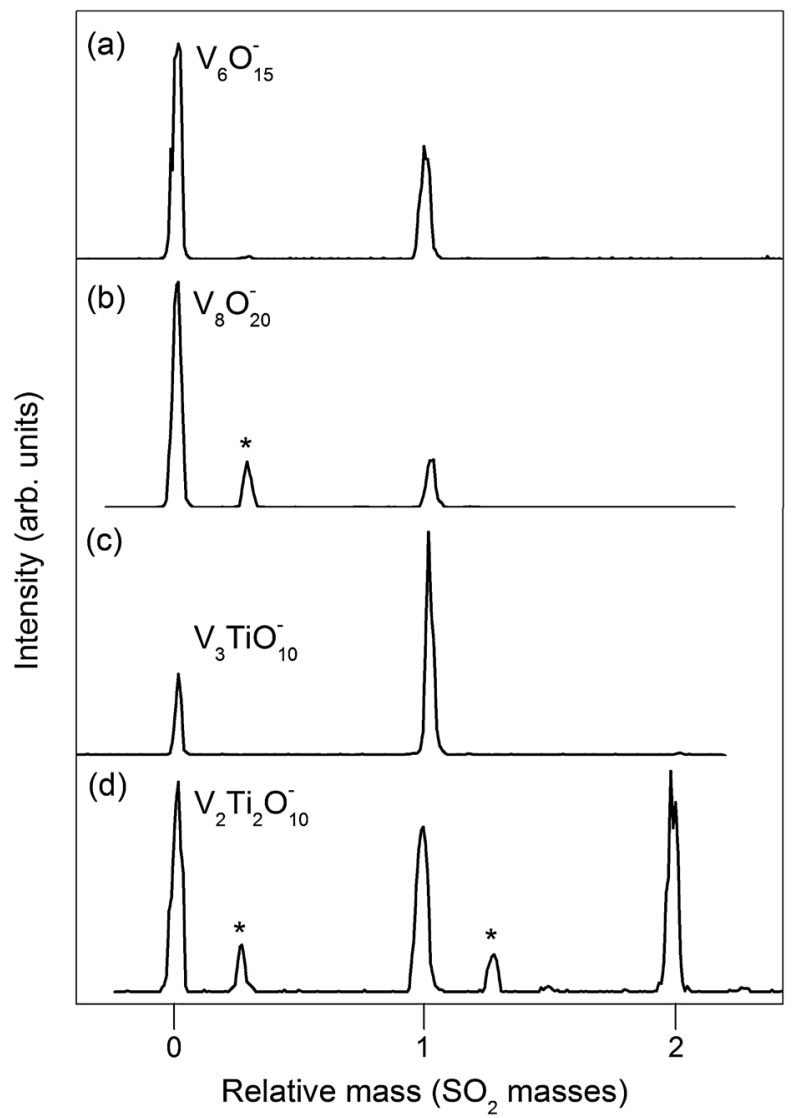

Fig. 5 Selected mass spectra obtained after reacting (a) $\mathrm{V}_{6} \mathrm{O}_{15}{ }^{-}$, (b) $\mathrm{V}_{8} \mathrm{O}_{20}{ }^{-}$, (c) $\mathrm{V}_{3} \mathrm{TiO}_{10}{ }^{-}$, and (d) $\mathrm{V}_{2} \mathrm{Ti}_{2} \mathrm{O}_{10}{ }^{-}$with $\mathrm{SO}_{2}$. (a) $T_{\mathrm{R}}=200 \mathrm{~K}$, $p\left(\mathrm{SO}_{2}\right)=(2.0 \pm 0.8) \times 10^{-4} \mathrm{~Pa}, t_{\mathrm{R}}=400 \mathrm{~ms}$; (b) $T_{\mathrm{R}}=200 \mathrm{~K}$, $p\left(\mathrm{SO}_{2}\right)=(4.0 \pm 1.0) \times 10^{-3} \mathrm{~Pa}, t_{\mathrm{R}}=600 \mathrm{~ms}$; (c) $T_{\mathrm{R}}=225 \mathrm{~K}, p\left(\mathrm{SO}_{2}\right)=$ $(4.0 \pm 1.3) \times 10^{-4} \mathrm{~Pa}, t_{\mathrm{R}}=600 \mathrm{~ms}$; (d) $T_{\mathrm{R}}=225 \mathrm{~K}, p\left(\mathrm{SO}_{2}\right)=$ $(4.0 \pm 1.6) \times 10^{-5} \mathrm{~Pa}, t_{\mathrm{R}}=800 \mathrm{~ms}$. Mass peaks denoted with an asterisk correspond to complexes containing $\mathrm{H}_{2} \mathrm{O}$.

temperatures in the range of $T_{\mathrm{R}}=150-275 \mathrm{~K}$. In order to observe distinct reaction products within the time scale of the experiment, the applied partial $\mathrm{SO}_{2}$ pressures are in the $3 \times$ $10^{-4}-5 \times 10^{-3} \mathrm{~Pa}\left(\mathrm{~V}_{4} \mathrm{O}_{10}{ }^{-}\right.$and $\left.\mathrm{V}_{8} \mathrm{O}_{20}{ }^{-}\right), 3 \times 10^{-5}-3 \times 10^{-4} \mathrm{~Pa}$ $\left(\mathrm{V}_{3} \mathrm{TiO}_{10}{ }^{-}\right.$and $\left.\mathrm{V}_{6} \mathrm{O}_{15}{ }^{-}\right)$, and $2 \times 10^{-5}-5 \times 10^{-5} \mathrm{~Pa}$ $\left(\mathrm{V}_{2} \mathrm{Ti}_{2} \mathrm{O}_{10}{ }^{-}\right)$ranges. Fig. 6 shows representative normalized product ion concentrations (open symbols) as a function of reaction time for $T_{\mathrm{R}}=200 \mathrm{~K}$ and the solid lines represent fits of integrated rate equations of the proposed reaction mechanisms that are discussed below.

Similar to $\mathrm{V}_{4} \mathrm{O}_{10}{ }^{-}$, the metal oxide clusters $\mathrm{V}_{6} \mathrm{O}_{15}{ }^{-}$and $\mathrm{V}_{3} \mathrm{TiO}_{10}{ }^{-}$adsorb, at all investigated ion trap temperatures, only one $\mathrm{SO}_{2}$ molecule forming the complexes $\left[\mathrm{V}_{6} \mathrm{O}_{15}, \mathrm{SO}_{2}\right]^{-}$ and $\left[\mathrm{V}_{3} \mathrm{TiO}_{10}, \mathrm{SO}_{2}\right]^{-}$, respectively. The kinetics of these reactions are also best described by an equilibrium reaction mechanism at $T_{\mathrm{R}} \geq 250 \mathrm{~K}$, while the backward reaction becomes negligible at $T_{\mathrm{R}}<250 \mathrm{~K}$. The termolecular rate constants $k_{\mathrm{f}}^{(3)}$ exhibit a clearly negative temperature dependence ( $c f$. Table 2), typically indicating energy barrier free adsorption of $\mathrm{SO}_{2}$. This finding does not contradict the modelled reaction profile for $\left[\mathrm{V}_{6} \mathrm{O}_{15}, \mathrm{SO}_{2}\right]^{-}$, predicting a considerable energy barrier for formation of the minimum energy structure.

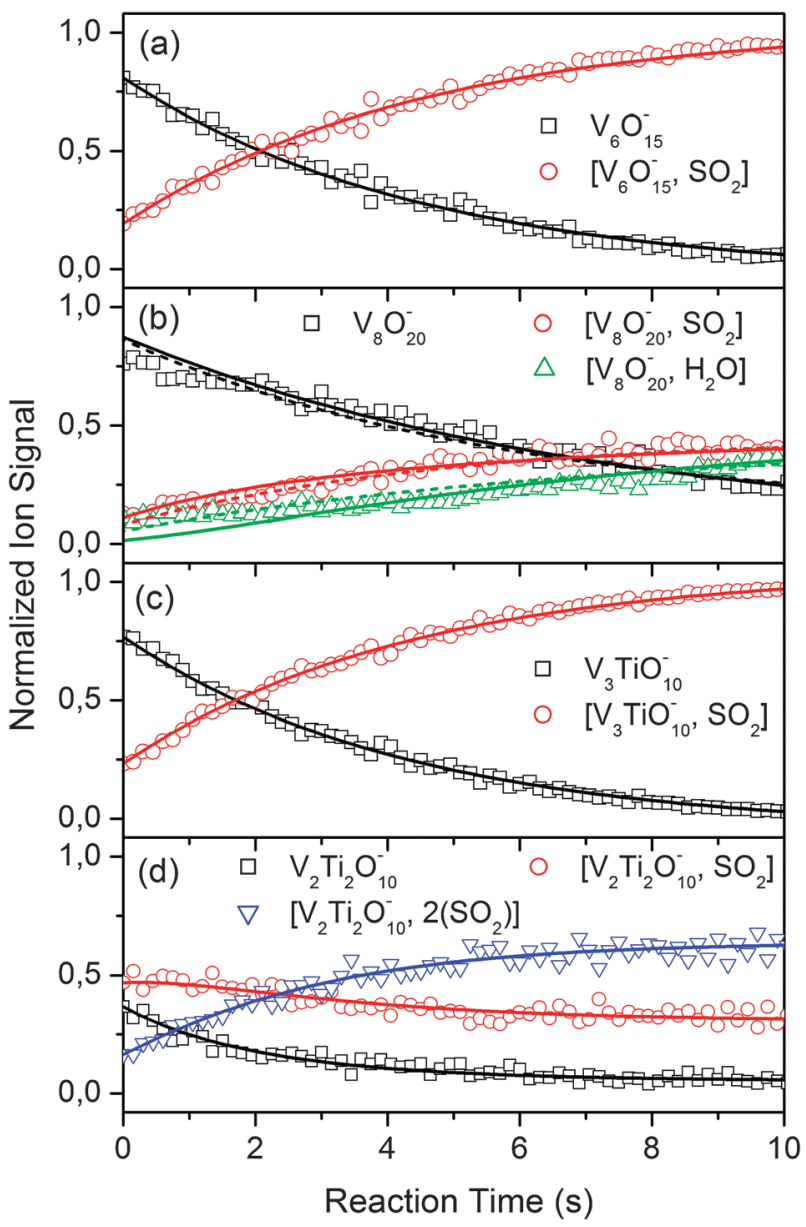

Fig. 6 Kinetic data of the reaction of (a) $\mathrm{V}_{6} \mathrm{O}_{15}{ }^{-}$, (b) $\mathrm{V}_{8} \mathrm{O}_{20}{ }^{-}$, (c) $\mathrm{V}_{3} \mathrm{TiO}_{10}{ }^{-}$, and (d) $\mathrm{V}_{2} \mathrm{Ti}_{2} \mathrm{O}_{10}{ }^{-}$with $\mathrm{SO}_{2}$ at $T_{\mathrm{R}}=200 \mathrm{~K}$. Open symbols represent the normalized intensities. The solid lines are obtained by fitting with the corresponding integrated rate equations as discussed in the text. The dashed lines in (b) are obtained by assuming a competing reaction according to eqn (5a) and (5b) while the solid lines correspond to a displacement reaction given in eqn (5a) and (6). Rate constants are given in Table 2.

As discussed above, the energy $E^{*}$ contained in the energized $\left[\mathrm{V}_{6} \mathrm{O}_{10}, \mathrm{SO}_{2}\right]^{-*}$ complex is considerably larger than the energy barrier for all investigated temperatures and thus should be easily surmounted and cannot be seen in the temperature dependent experimental kinetic data. In fact, the strictly negative temperature dependence in the whole investigated temperature range indicates that the energy barrier can even be overcome at the lowest investigated reaction temperature of $T_{\mathrm{R}}=175 \mathrm{~K}$. The reaction does not stop at $\mathbf{C}$ as this should cause a considerable increase in $k_{\mathrm{d}}$ at low temperatures according to an RRKM estimate of the decomposition rate constants.

For $\mathrm{V}_{8} \mathrm{O}_{20}{ }^{-}$not only the $\mathrm{SO}_{2}$ complex $\left[\mathrm{V}_{8} \mathrm{O}_{20}, \mathrm{SO}_{2}\right]^{-}$, but also a water containing complex $\left[\mathrm{V}_{8} \mathrm{O}_{20}, \mathrm{H}_{2} \mathrm{O}\right]^{-}$was recorded (cf. Fig. 5(b) and 6(b)). The $\mathrm{H}_{2} \mathrm{O}$ presence indicates contamination of the inlet tubes and the ion trap, which are nonbakeable. $\left[\mathrm{V}_{8} \mathrm{O}_{20}, \mathrm{H}_{2} \mathrm{O}\right]^{-}$has a high abundance relative to the amount of $\mathrm{SO}_{2}$ complexes. Therefore, the reaction with $\mathrm{H}_{2} \mathrm{O}$ must be taken into account in the reaction kinetics. 
Table 2 Measured termolecular $k_{\mathrm{f}}^{(3)}$ rate constants for the forward reaction between the metal oxide clusters and $\mathrm{SO}_{2}$ and corresponding unimolecular decomposition rate constant $k_{\mathrm{d}}$ of the energized complex as a function of the reaction temperature $T_{\mathrm{R}}$

\begin{tabular}{lccc}
\hline & $T_{\mathrm{R}} / \mathrm{K}$ & $k_{\mathrm{f}}{ }^{(3)} / 10^{-28} \mathrm{~cm}^{6} \mathrm{~s}^{-1}$ & $k_{\mathrm{d}} / 10^{9} \mathrm{~s}^{-1}$ \\
\hline $\mathrm{V}_{6} \mathrm{O}_{15}{ }^{-}$ & 175 & $520 \pm 240$ & $0.015 \pm 0.007$ \\
& 200 & $120 \pm 50$ & $0.064 \pm 0.029$ \\
& 225 & $70 \pm 30$ & $0.11 \pm 0.06$ \\
$\mathrm{~V}_{8} \mathrm{O}_{20}{ }^{-}$ & 250 & $43 \pm 25$ & $0.16 \pm 0.10$ \\
& 150 & $12 \pm 5^{a}$ & $0.68 \pm 0.30$ \\
& 175 & $6.5 \pm 1.6^{b}$ & $2.4 \pm 1.1$ \\
& 200 & $0.47 \pm 0.5^{a}$ & $1.2 \pm 0.4$ \\
& 225 & $0.29 \pm 0.12^{b}$ & $4.7 \pm 1.8$ \\
& 150 & $200 \pm 10030$ & $16 \pm 7$ \\
$\mathrm{~V}_{3} \mathrm{TiO}_{10}{ }^{-}$ & 175 & $160 \pm 70$ & $26 \pm 11$ \\
& 200 & $80 \pm 30$ & $91 \pm 34$ \\
& 225 & $60 \pm 19$ & $0.045 \pm 0.024$ \\
& 250 & $38 \pm 16$ & $0.051 \pm 0.023$ \\
& 275 & $13 \pm 6$ & $0.10 \pm 0.03$ \\
$\mathrm{~V}_{2} \mathrm{Ti}_{2} \mathrm{O}_{10}{ }^{-}$ & 200 & $500 \pm 250$ & $0.13 \pm 0.05$ \\
& 225 & $660 \pm 340$ & $0.53 \pm 0.08$ \\
& 250 & $130 \pm 70$ & $0.016 \pm 0.008$ \\
& & & $0.011 \pm 0.006$ \\
& & & $0.055 \pm 0.028$
\end{tabular}

${ }^{a}$ Assuming a $\mathrm{H}_{2} \mathrm{O} / \mathrm{SO}_{2}$ displacement reaction (eqn (5a) and (5b)). ${ }^{b}$ Assuming a $\mathrm{H}_{2} \mathrm{O} / \mathrm{SO}_{2}$ competing reaction (eqn (5a) and (6)).

The formation of $\left[\mathrm{V}_{8} \mathrm{O}_{20}, \mathrm{SO}_{2}\right]^{-}$and $\left[\mathrm{V}_{8} \mathrm{O}_{20}, \mathrm{H}_{2} \mathrm{O}\right]^{-}$might result from competitive $\mathrm{SO}_{2}$ and $\mathrm{H}_{2} \mathrm{O}$ adsorption on $\mathrm{V}_{8} \mathrm{O}_{20}{ }^{-}$:

$$
\begin{gathered}
\mathrm{V}_{8} \mathrm{O}_{20}{ }^{-}+\mathrm{SO}_{2} \rightleftarrows\left[\mathrm{V}_{8} \mathrm{O}_{20}, \mathrm{SO}_{2}\right]^{-} k_{\mathrm{f}}, k_{\mathrm{b}} \\
\mathrm{V}_{8} \mathrm{O}_{20}{ }^{-}+\mathrm{H}_{2} \mathrm{O} \rightleftarrows\left[\mathrm{V}_{8} \mathrm{O}_{20}, \mathrm{H}_{2} \mathrm{O}\right]^{-}
\end{gathered}
$$

An alternative possible reaction mechanism is first formation of the $\left[\mathrm{V}_{8} \mathrm{O}_{20}, \mathrm{SO}_{2}\right]^{-}$complex, according to eqn (5a), and the subsequent displacement of $\mathrm{SO}_{2}$ by $\mathrm{H}_{2} \mathrm{O}$ :

$$
\left[\mathrm{V}_{8} \mathrm{O}_{20}, \mathrm{SO}_{2}\right]^{-}+\mathrm{H}_{2} \mathrm{O} \leftrightarrows\left[\mathrm{V}_{8} \mathrm{O}_{20}, \mathrm{H}_{2} \mathrm{O}\right]^{-}+\mathrm{SO}_{2}
$$

The lines in Fig. 6(b) represent the fits of the competing (dashed lines) and displacement (solid lines) reaction mechanism to the experimental kinetic data, both exhibiting comparable fit quality. Thus, none of the proposed reaction mechanisms can be unambiguously assigned and in Table 2 the termolecular rate constants obtained by fitting both mechanisms are listed. Since $\mathrm{H}_{2} \mathrm{O}$ is only present in the ion trap as a residual gas and thus of unknown concentration, the reaction steps (5b) and (6) are not further discussed. At the highest investigated reaction temperature, $T_{\mathrm{R}}=225 \mathrm{~K}$, the intensity of the $\mathrm{H}_{2} \mathrm{O}$ complexes was very small and eqn (5a) was used to fit the data.

In contrast to $\mathrm{V}_{4} \mathrm{O}_{10}{ }^{-}, \mathrm{V}_{6} \mathrm{O}_{15}{ }^{-}, \mathrm{V}_{8} \mathrm{O}_{20}{ }^{-}$, and $\mathrm{V}_{3} \mathrm{TiO}_{10}{ }^{-}$, which only adsorb one $\mathrm{SO}_{2}$ molecule, the bimetallic oxide cluster $\mathrm{V}_{2} \mathrm{Ti}_{2} \mathrm{O}_{10}{ }^{-}$is more reactive. From Fig. 6(d) it is apparent that the first formed product $\left[\mathrm{V}_{2} \mathrm{Ti}_{2} \mathrm{O}_{10}, \mathrm{SO}_{2}\right]^{-}$ further reacts under the addition of a second $\mathrm{SO}_{2}$ ligand, yielding $\left[\mathrm{V}_{2} \mathrm{Ti}_{2} \mathrm{O}_{10}, 2 \mathrm{SO}_{2}\right]^{-}$. The reaction mechanism that best fits the kinetic data is given by:

$$
\begin{aligned}
& \mathrm{V}_{2} \mathrm{Ti}_{2} \mathrm{O}_{10}^{-}+\mathrm{SO}_{2} \rightleftarrows\left[\mathrm{V}_{2} \mathrm{Ti}_{2} \mathrm{O}_{10}, \mathrm{SO}_{2}\right]^{-} k_{\mathrm{f}}, k_{\mathrm{b}} \\
& {\left[\mathrm{V}_{2} \mathrm{Ti}_{2} \mathrm{O}_{10}, \mathrm{SO}_{2}\right]^{-}+\mathrm{SO}_{2} \rightleftarrows\left[\mathrm{V}_{2} \mathrm{Ti}_{2} \mathrm{O}_{10}, 2 \mathrm{SO}_{2}\right]^{-}}
\end{aligned}
$$

and the fits are shown as solid lines in Fig. 6(d). Besides $\left[\mathrm{V}_{2} \mathrm{Ti}_{2} \mathrm{O}_{10}, \mathrm{SO}_{2}\right]^{-}$and $\left[\mathrm{V}_{2} \mathrm{Ti}_{2} \mathrm{O}_{10}, 2 \mathrm{SO}_{2}\right]^{-}$two additional low intensity products are detected, corresponding to the water complexes $\left[\mathrm{V}_{2} \mathrm{Ti}_{2} \mathrm{O}_{10}, \mathrm{H}_{2} \mathrm{O}\right]^{-}$and $\left[\mathrm{V}_{2} \mathrm{Ti}_{2} \mathrm{O}_{10}, \mathrm{SO}_{2}, \mathrm{H}_{2} \mathrm{O}\right]^{-}$ (cf. Fig. 5(d)). However, since these $\left[\mathrm{V}_{2} \mathrm{Ti}_{2} \mathrm{O}_{10}, \mathrm{H}_{2} \mathrm{O}\right]^{-}$complexes are only detected at the lowest investigated reaction temperatures and are present in significantly smaller amounts than the $\mathrm{SO}_{2}$ complexes, they can be neglected in the fitting procedure. Eqn (7a) and (7b) describe the reaction of $\mathrm{V}_{2} \mathrm{Ti}_{2} \mathrm{O}_{10}{ }^{-}$with $\mathrm{SO}_{2}$ satisfactorily.

Similar to $\mathrm{V}_{4} \mathrm{O}_{10}{ }^{-}$and $\mathrm{V}_{6} \mathrm{O}_{15}{ }^{-}$, also $\mathrm{V}_{8} \mathrm{O}_{20}{ }^{-}$and the $\mathrm{Ti}$ doped clusters $\mathrm{V}_{3} \mathrm{TiO}_{10}{ }^{-}$and $\mathrm{V}_{2} \mathrm{Ti}_{2} \mathrm{O}_{10}{ }^{-}$exhibit a negative temperature dependence of $k_{\mathrm{f}}^{(3)}$, indicating either a barrierfree adsorption of $\mathrm{SO}_{2}$ or activation barriers that can be easily surmounted in the whole investigated temperature range.

\section{D.3 Size and composition dependence}

For none of the clusters investigated here, evidence for the formation of $\mathrm{SO}_{3}$ was found. This is in line with the calculations by Jakubikova and Bernstein, who demonstrated that only oxygen-rich vanadium oxide clusters convert $\mathrm{SO}_{2}$ into $\mathrm{SO}_{3} .{ }^{15}$ The reaction constants for the $\mathrm{SO}_{2}$ association and desorption reactions appear to depend strongly on the cluster size and composition. The rate constants increase upon titanium for vanadium substitution and are higher for $\mathrm{V}_{6} \mathrm{O}_{15}$ than for $\mathrm{V}_{4} \mathrm{O}_{10}{ }^{-}$or $\mathrm{V}_{8} \mathrm{O}_{20}{ }^{-}$. Since the size and composition dependence of $k_{\mathrm{a}}$ and $k_{\mathrm{s}}$ are marginal, an increase in the termolecular rate constant is according to eqn (3) caused by a decreased unimolecular rate constant $k_{\mathrm{d}}$ or an increased life time of the energized complex $\left[\mathrm{V}_{m} \mathrm{Ti}_{n} \mathrm{O}_{o}, \mathrm{SO}_{2}\right]^{-*}$. Three factors (or a combination of them) can cause this increased life time: (i) a higher $\mathrm{SO}_{2}$ binding energy to the cluster, (ii) a higher activation barrier for formation of a stable complex which hampers the unimolecular dissociation, and (iii) a higher number of degrees of freedom among which the energy gained upon complex formation can be redistributed. The last factor is only relevant when comparing reaction rates of clusters with different size.

Based on these three factors the cluster size dependent reactivity toward $\mathrm{SO}_{2}$ can be understood. The unimolecular decomposition of $\left[\mathrm{V}_{6} \mathrm{O}_{15}, \mathrm{SO}_{2}\right]^{-*}$ is found to be slower than that of $\left[\mathrm{V}_{4} \mathrm{O}_{10}, \mathrm{SO}_{2}\right]^{-*}$. Factor (i) does not explain this observation since the $\mathrm{SO}_{2}$ binding energy to $\mathrm{V}_{6} \mathrm{O}_{15}{ }^{-}$is $0.58 \mathrm{eV}$, which is lower than the corresponding value for $\mathrm{V}_{4} \mathrm{O}_{10}{ }^{-}$ $(0.70 \mathrm{eV})$. It is the activation barrier (TS1 at $+0.58 \mathrm{eV})$ for formation of the minimum energy structure $A$ of $\left[\mathrm{V}_{6} \mathrm{O}_{15}\right.$, $\left.\mathrm{SO}_{2}\right]^{-*}$ which reduces the unimolecular dissociation rate constant $k_{\mathrm{d}}$, i.e. factor (ii). In addition, the increased number of vibrational degrees of freedom in the larger $\left[\mathrm{V}_{6} \mathrm{O}_{15}, \mathrm{SO}_{2}\right]^{-*}$ complex compared to $\left[\mathrm{V}_{4} \mathrm{O}_{10}, \mathrm{SO}_{2}\right]^{-*}$ further increases the life time of the energized complex. The largest investigated vanadium oxide cluster $\left[\mathrm{V}_{8} \mathrm{O}_{20}, \mathrm{SO}_{2}\right]^{-*}$ exhibits unimolecular decomposition rate constants $k_{\mathrm{d}}$, which are up to one order of magnitude larger (depending on the reaction temperature and the proposed reaction mechanism) than those of $\left[\mathrm{V}_{4} \mathrm{O}_{10}, \mathrm{SO}_{2}\right]^{-*}$. The high unimolecular decomposition rate of $\left[\mathrm{V}_{8} \mathrm{O}_{20}, \mathrm{SO}_{2}\right]^{-*}$ cannot be explained by factors (ii) and (iii). The larger complex $\left[\mathrm{V}_{8} \mathrm{O}_{20}, \mathrm{SO}_{2}\right]^{-*}$ comprises nearly twice as many vibrational 
degrees of freedom as $\left[\mathrm{V}_{4} \mathrm{O}_{10}, \mathrm{SO}_{2}\right]^{-*}$. In addition, the energy profile of the reaction of $\mathrm{V}_{4} \mathrm{O}_{10}{ }^{-}$with $\mathrm{SO}_{2}$ reveals only marginal energy barriers for formation of isomer $\mathbf{A}$ (see Fig. 2). Consequently, the reactivity of $\mathrm{V}_{8} \mathrm{O}_{20}{ }^{-}$can only be explained by a lower binding energy of the $\mathrm{SO}_{2}$ molecule.

$\mathrm{V}_{4} \mathrm{O}_{10}{ }^{-}, \mathrm{V}_{3} \mathrm{TiO}_{10}{ }^{-}$, and $\mathrm{V}_{2} \mathrm{Ti}_{2} \mathrm{O}_{10}{ }^{-}$all contain the same number of atoms and thus the same number of vibrational degrees of freedom to accommodate the energy gained upon reaction with $\mathrm{SO}_{2}$. However, they exhibit very different reactivity with unimolecular decomposition rate constants differing by up to three orders of magnitude depending on $T_{\mathrm{R}}$. Independent of the composition, the clusters have a tetrahedral shape. ${ }^{25}$ However, electronically they are very different. While $\mathrm{V}_{4} \mathrm{O}_{10}{ }^{-}$has a single unpaired electron, $\mathrm{V}_{3} \mathrm{TiO}_{10}{ }^{-}$is a closed shell species isoelectronic with the neutral $\mathrm{V}_{4} \mathrm{O}_{10}$. It has fully oxidized vanadium and titanium atoms, in which the V, Ti and $\mathrm{O}$ atoms carry a formal valence of $+\mathrm{v}$, $+\mathrm{IV}$, and $-\mathrm{II}$, respectively. Although $\mathrm{V}_{3} \mathrm{TiO}_{10}{ }^{-}$is a closed shell species, it surprisingly is more reactive than $\mathrm{V}_{4} \mathrm{O}_{10}{ }^{-}$. The reason for the higher reactivity of $\mathrm{V}_{3} \mathrm{TiO}_{10}{ }^{-}$likely is the charge localization on the outer oxygen atom that binds with the titanium and acts as the active site for the $\mathrm{SO}_{2}$ adsorption. $\mathrm{V}_{2} \mathrm{Ti}_{2} \mathrm{O}_{10}{ }^{-}$has a doublet ground state with a free radical localized on a singly titanium-bonded terminal oxygen atom. ${ }^{25}$ This radical is likely transferred to the first $\mathrm{SO}_{2}$ molecule. The second $\mathrm{SO}_{2}$ molecule can then bind to a similar site as in $\mathrm{V}_{3} \mathrm{TiO}_{10}{ }^{-}$. The presence of the oxygen radical explains the much higher reactivity of $\mathrm{V}_{2} \mathrm{Ti}_{2} \mathrm{O}_{10}{ }^{-}$and the observation that it likes to bind two $\mathrm{SO}_{2}$ molecules.

\section{E. Conclusions}

Using gas phase IRMPD spectroscopy in conjunction with DFT calculations we have shown that upon adsorption the $\mathrm{SO}_{2}$ molecule is incorporated in the vanadium-oxide framework of $\mathrm{V}_{4} \mathrm{O}_{10}{ }^{-}$. The $\left[\mathrm{V}_{4} \mathrm{O}_{10}, \mathrm{SO}_{2}\right]^{-}$complex has a square pyramidal structure similar to $\mathrm{V}_{5} \mathrm{O}_{13}{ }^{-}$where one of the $\mathrm{O}=\mathrm{VO}_{3 / 2}$ corners of the square has been replaced by $\mathrm{S}^{(+)} \mathrm{O}_{3 / 2}$, and the $\mathrm{O}=\mathrm{V}\left(\mathrm{d}^{0}\right)^{(-)} \mathrm{O}_{4 / 2}$ top site has been replaced by a $\mathrm{O}=\mathrm{V}\left(\mathrm{d}^{1}\right)^{(2-)} \mathrm{O}_{4 / 2}$ site with the unpaired electron localized in d-states of this vanadium atom. The calculated $\mathrm{SO}_{2}$ binding energy of $0.70 \mathrm{eV}$ agrees nicely with the experimental value of $E_{0}=0.72 \pm 0.12 \mathrm{eV}$, which was determined from the kinetic data using the Lindemann energy transfer model for association reactions in conjunction with statistical RRKM theory.

The reaction energy profiles of $\mathrm{V}_{4} \mathrm{O}_{10}{ }^{-}+\mathrm{SO}_{2}$ and $\mathrm{V}_{6} \mathrm{O}_{15}{ }^{-}+\mathrm{SO}_{2}$ have been modelled. Whereas the transition states in the reaction of $\mathrm{V}_{4} \mathrm{O}_{10}{ }^{-}$with $\mathrm{SO}_{2}$ have energies below that of the separated partners, the reaction of $\mathrm{V}_{6} \mathrm{O}_{15}{ }^{-}$with $\mathrm{SO}_{2}$ proceeds via a transition state with energy higher than the ground state energy of the educts.

The role of cluster size and composition is investigated by studying the reaction kinetics of larger $\left(\mathrm{V}_{6} \mathrm{O}_{15}{ }^{-}\right.$and $\left.\mathrm{V}_{8} \mathrm{O}_{20}{ }^{-}\right)$ and titanium doped $\left(\mathrm{V}_{3} \mathrm{TiO}_{10}{ }^{-}\right.$and $\left.\mathrm{V}_{2} \mathrm{Ti}_{2} \mathrm{O}_{10}{ }^{-}\right)$vanadium oxide clusters with $\mathrm{SO}_{2}$. The cluster size dependence is discussed in terms of three factors: (1) the $\mathrm{SO}_{2}$ binding energy, (2) activation barriers involved in the formation of the minimum energy structure, and (3) the number of vibrational degrees of freedom which are available to accommodate the energy gained upon reaction.
The higher reactivity of the titanium doped clusters is attributed to the charge localization on the outer oxygen atom that binds with the titanium atom in $\mathrm{V}_{3} \mathrm{TiO}_{10}{ }^{-}$. The presence of a free radical localized on a singly titanium-bonded terminal oxygen atom in $\mathrm{V}_{2} \mathrm{Ti}_{2} \mathrm{O}_{10}{ }^{-}$allows binding of a second $\mathrm{SO}_{2}$ molecule.

The results of the present gas phase study provide new ideas about the reaction mechanism of vanadium oxide nanoparticles with $\mathrm{SO}_{2}$, which are of relevance for a deeper understanding and eventually further optimization of specific catalytic cycles such as the $\mathrm{SO}_{3}$ production from $\mathrm{SO}_{2}$ using vanadium oxide particles.

\section{Acknowledgements}

This work has been supported by the German Research Foundation (DFG) within the Center of Collaborative Research "Transition metal oxide aggregates" (SFB-546) and by the KU Leuven Research Council (GOA program). We acknowledge the support of the Stichting voor Fundamenteel Onderzoek der Materie (FOM) in providing the required beam time on FELIX and highly appreciate the skilful assistance of the FELIX staff. S.M.L. is grateful for support from the Research Foundation - Flanders (FWO).

\section{References}

1 G. Ertl, H. Knotzinger and J. Weitkamp, Handbook of Heterogeneous Catalysis, Wiley-VCH, Weinheim, 1997.

2 J. P. Dunn, H. G. Stenger and I. E. Wachs, Catal. Today, 1999, 51, 301.

3 P. J. Chenier, Survey of Industrial Chemistry, Kluwer, New York, 3rd edn, 2002.

4 O. B. Lapina, B. S. Bal'zhinimaev, S. Boghosian, K. M. Eriksen and R. Fehrmann, Catal. Today, 1999, 51, 469

5 A. J. Leavitt, R. B. Wyrwas, W. T. Wallace, D. S. Serrano, M. G. Arredondo, L. M. Leslie, F. A. Khan and R. L. Whetten, J. Phys. Chem. A, 2005, 109, 6218.

6 R. C. Bell, K. A. Zemski, D. R. Justes and A. W. Castleman, Jr., J. Chem. Phys., 2001, 114, 798.

7 K. A. Zemski, D. R. Justes and A. W. Castleman, Jr., J. Phys. Chem. A, 2001, 105, 10237.

8 S. Feyel, J. Döbler, D. Schröder, J. Sauer and H. Schwarz, Angew. Chem., Int. Ed., 2006, 45, 4681.

9 S. Feyel, D. Schröder and H. Schwarz, J. Phys. Chem. A, 2006, 110, 2647.

10 S. Li, A. Mirabal, J. Demuth, L. Wöste and T. Siebert, J. Am. Chem. Soc., 2008, 130, 16832

11 Y. X. Zhao, X. N. Wu, J. B. Ma, S. G. He and X. L. Ding, J. Phys. Chem. C, 2010, 114, 12271.

12 A. Fielicke, R. Mitrić, G. Meijer, V. Bonačić-Koutecký and G. Von Helden, J. Am. Chem. Soc., 2003, 125, 15716.

13 T. Wende, J. Döbler, L. Jiang, P. Claes, E. Janssens, P. Lievens, G. Meijer, K. R. Asmis and J. Sauer, Int. J. Mass Spectrom., 2010, 297, 102.

14 R. B. Wyrwas, Vanadium Oxide Anion Clusters: Their Abdundances, Structures, and Reactions with $\mathrm{SO}_{2}$, Georgia Institute of Technology, 2004.

15 E. Jakubikova and E. R. Bernstein, J. Phys. Chem. A, 2007, 111, 13339.

16 S. G. He, Y. Xie, F. Dong, S. Heinbuch, E. Jakubikova, J. J. Rocca and E. R. Bernstein, J. Phys. Chem. A, 2007, 111, 13339.

17 A. Fielicke and K. Rademann, Phys. Chem. Chem. Phys., 2002, 4, 2621.

18 K. R. Asmis, G. Santambrogio, M. Brümmer and J. Sauer, Angew. Chem., Int. Ed., 2005, 44, 3122. 
19 K. R. Asmis, M. Brümmer, C. Kaposta, G. Santambrogio, G. von Helden, G. Meijer, K. Rademann and L. Wöste, Phys. Chem. Chem. Phys., 2002, 4, 1101.

20 M. Brümmer, C. Kaposta, G. Santambrogio and K. R. Asmis, J. Chem. Phys., 2003, 119, 12700.

21 K. R. Asmis, G. Meijer, M. Brümmer, C. Kaposta, G. Santambrogio, L. Wöste and J. Sauer, J. Chem. Phys., 2004, 120, 6461.

22 G. Santambrogio, M. Brümmer, L. Wöste, J. Döbler, M. Sierka, J. Sauer, G. Meijer and K. R. Asmis, Phys. Chem. Chem. Phys., 2008, 10, 3992.

23 S. F. Vyboishchikov and J. Sauer, J. Phys. Chem. A, 2001, 105, 8588 .

24 K. R. Asmis, T. Wende, M. Brümmer, O. Gause, G. Santambrogio, E. C. Stanca-Kaposta, J. Döbler, A. Niedziela and J. Sauer, Phys. Chem. Chem. Phys., 2012, 14, 9377.

25 E. Janssens, G. Santambrogio, M. Brümmer, L. Wöste, P. Lievens, J. Sauer, G. Meijer and K. R. Asmis, Phys. Rev. Lett., 2006, 96, 233401.

26 H. J. Zhai and L. S. Wang, J. Chem. Phys., 2002, 117, 7882.

27 K. R. Asmis, M. Brümmer, C. Kaposta, G. Santambrogio, G. v. Helden, G. Meijer, K. Rademann and L. Wöste, Phys. Chem. Chem. Phys., 2002, 4, 1101.

28 E. Janssens, H. Tanaka, S. Neukermans, R. E. Silverans and P. Lievens, Phys. Rev. B: Condens. Matter Mater. Phys., 2004, 69, 085402 .

29 T. M. Bernhardt, Int. J. Mass Spectrom., 2005, 243, 1.

30 D. Oepts, A. F. G. van der Meer and P. W. van Amersfoort, Infrared Phys. Technol., 1995, 36, 297.

31 T. M. Bernhardt, J. Hagen, S. M. Lang, D. M. Popolan, L. D. Socaciu-Siebert and L. Wöste, J. Phys. Chem. A, 2009, 113, 2724.

32 E. Schuhmacher, DETMECH - Chemical Reaction Kinetics Software, University of Bern, 2003 (http://www.chemsoft.ch).

33 J. I. Steinfeld, J. S. Francisco and W. L. Hase, Chemical Kinetics and Dynamics, Prentice Hall, Upper Saddle River, 2nd ed., 1999.
34 P. Langevin, Ann. Chim. Phys., 1905, 5, 245.

35 Handbook of Chemistry and Physics, ed. D. R. Lide, CRC, Boca Raton, 1995.

36 D. Patel, D. Margolese and T. R. Dyke, J. Chem. Phys., 1979, 70, 2740 .

37 T. Su, J. Chem. Phys., 1988, 89, 5354.

38 R. A. Marcus, J. Chem. Phys., 1952, 20, 359.

39 K. A. Holbrook, M. J. Pillings and S. H. Robertson, Unimolecular Reactions, Wiley, Chichester, 2nd ed., 1996.

40 L. Drahos and K. Vékey, J. Mass Spectrom., 2001, 36, 237.

41 R. Ahlrichs, M. Bär, M. Häser, H. Horn and C. Kölmel, Chem. Phys. Lett., 1989, 162, 165.

42 A. D. Becke, Phys. Rev. A, 1988, 38, 3098.

43 A. Schäfer, C. Huber and R. Ahlrichs, J. Chem. Phys., 1994, 100, 5829.

44 A. J. Wachters, J. Chem. Phys., 1970, 52, 1033.

45 C. W. Bauschlicher, Jr. and H. Partridge, Chem. Phys. Lett., 1995, 240, 533.

46 T. H. Dunning, Jr., K. A. Peterson and A. K. Wilson, J. Chem. Phys., 2001, 114, 9244.

47 P. Deglmann, F. Furche and R. Ahlrichs, Chem. Phys. Lett., 2002, 362, 511 .

48 K. R. Asmis and J. Sauer, Mass Spectrom. Rev., 2007, 26, 542.

49 W. B. Person and G. Zerbi, Vibrational Intensities in Infrared and Raman Spectroscopy, Elsevier, Amsterdam, 1982.

50 S. M. Lang, T. M. Bernhardt, R. N. Barnett and U. Landman, ChemPhysChem, 2010, 11, 1570.

51 V. A. Spasov, T. H. Lee, J. P. Maberry and K. M. Ervin, J. Chem. Phys., 1999, 110, 5208.

52 M. F. Jarrold and J. E. Bower, J. Chem. Phys., 1987, 87, 5728.

53 S. Boghosian, J. Chem. Soc., Faraday Trans., 1998, 94, 3463.

54 I. Giakoumelou, R. M. Caraba, V. I. Parvulescu and S. Boghosian, Catal. Lett., 2002, 78, 209.

55 D. M. Cox, K. C. Reichmann, D. J. Trevor and A. Kaldor, J. Chem. Phys., 1988, 88, 111. 